\title{
Reasons of Tax Avoidance and Tax Evasion: Reflections from Pakistan
}

\author{
Muhammad Muazzam Mughal, *Muhammad Akram \\ Hailey College of Commerce University of the Punjab, Lahore-Pakistan \\ *makram.hcc.pu.edu.pk@gmail.com
}

\begin{abstract}
Amount of taxes serves as life blood for government. This paper aims to recognize reasons/causes of tax avoidance and evasion in Pakistan. Relationship between variables of reasons/causes of tax avoidance and evasion are also examined. A questionnaire is developed after reviewing literature to collect responses. Data are analyzed using percentages, arithmetic mean, standard deviation, variance, central limit theorem, cumulative normal distribution calculator, factor analysis, and correlation technique. Results indicate that all variables of reasons/causes of tax avoidance and evasion in Pakistan are correct. Furthermore, there exists a highly significant positive relationship between individual variables of reasons/causes of tax avoidance and evasion in Pakistan at $100 \%$ significance level.
\end{abstract}

Keywords: Tax evasion, Tax avoidance, Causes, Central Limit Theorem, Pakistan.

\section{Introduction}

Economic development is essential factor for every country in the world and government services and public infrastructure are also required for economic development. Lacking in public service provisions subverts the efforts to increase people living standard especially in developing countries and slow down the economic growth. It has also observed that governments of many developing countries have failed to provide adequate public services due to many reasons. The most important of them is the lack of tax revenue. Tax revenue in a country serves as life blood for the government: whereas; the ratio between average revenue and gross domestic product (GDP) in developed countries was almost 35\% in 2005 . In developing countries, this ratio was almost $15 \%$, while in third world countries tax revenue ratio was $12 \%$ of gross domestic product. This gross domestic product (GDP) gap can be elucidated to some extent through this fact that demand increases more for public services as compared to the increase of demand for income. This phenomenon also shows that these countries are lacking in the ability to increase the tax revenue at required level to provide the sufficient public services. The political and academic debates have raised many issues regarding development aid and finance. Development aid and finance shows the ability of a country to finance the public sector which may undermine due to tax evasion and avoidance. On the other hand, it is also perceived that both tax avoidance and tax evasion are linked with shadow economy and Schneider and Enste (2000) reported that shadow economy is that economy in which people do not show their real income and taxable income that they have earned through legal activities including barter and monitory activities in order to avoid paying tax.

Every patriotic citizen has a desire to strengthen one's society. It is their public duty to make tax payment and they also try to fulfill their desires by making tax payments to the government because taxes are the major sources of income for government and government use this money to provide services to general public such as defense, public utilities, transportation, education, roads etc. But tax avoidance and tax evasion are also exist and considered as major problems for the Pakistan that create interruption in the working of government to provide the services to general public. Tax avoidance can be defined as the activity of tax payers in which they try to find out different ways to lessen or eliminate his tax liability and do not show their legal income without violating law, whereas, tax evasion can be described as the activity of taxpayers in which they wayward and premeditated infringement of law for the purpose of escaping tax payments that has been indisputably inflicted by the tax authority. These two evil spirits have generated a gap among probable and actual government revenues. Government has protested against these two above mentioned evils for number of times but corporations and all other persons whose income is taxable, they make use of the tax avoidance strategies to get away or curtail the taxes or they willfully employ fake techniques with the support of the tax officials to evade the total tax.

Amount of taxes is essential in every economy for development. In case of Pakistan, some people individually as well as corporations pay tax but most of the people and corporations are not paying tax to 
relevant tax authority, although, amount of tax will spend on citizens of Pakistan. Obviously, there must be some reasons for non-payment of tax. In this paper, an initial step is taken to explore causes/reasons of tax avoidance and evasion in Pakistan. The main objectives of this study are to explore different factors regarding causes/reasons of tax avoidance and evasion, which are highly preferred by the individual taxpayers in Pakistan, in result, they try to avoid and evade amount of tax; and examine the relationship between identified factors of causes/reasons of tax avoidance and evasion in Pakistan.

It is an initial step undertaken with a view to explore different factors of causes/reasons of tax avoidance and evasion in Pakistan. In this study, only views of individual taxpayers are incorporated and corporations are not entertained. This study will, ultimately, provide base for further research through entertaining corporations along with individual taxpayers in finding out the reasons/causes of tax avoidance tax evasion in Pakistan. It will also assist relevant tax authority to understand the causes/reasons of tax avoidance and evasion, so that new policies will be developed and implemented to reduce the size of shadow economy through removing current and potential causes/ reasons of tax evasion and avoidance. This study is organized as: introduction is defined in Section 1. Literature review is described in Section 2. Theoretical background is explained in Section 3. Research methodology is demonstrated in Section 4. Results are clarified in Section 5. Conclusions are stated in Section 6. Limitations, future prospects, and policy implications are reported in Section 7.

\section{Review of Literature}

Lefebvre et al. (2011) conducted study in Netherlands, France and Belgium (Flanders and Wallonia) while examining the behavior of people. He compared the behavior of people regarding welfare dodging and tax evasion. Results indicated that: people adopt less evaded behavior in tax treatment than in welfare treatment; and people evade more tax in Netherlands and France but tax evasion is more in Flemish than Walloons. Uadiale et al. (2010) conducted study in Nigeria while examining relationship between personal income tax evasion and cultural factors like religiosity, trust in government, and legal enforcement. Study found positive impact on personal income tax of trust in government and legal enforcement. However, no significant relationship found between religious variables and tax evasion in Nigeria. Boylan and Sprinkle (2001) conducted study in which he tried to explore the behavioral determinants of tax evasion. He used experiment technique in order to acquire desired objectives such as to identify the factors that motivate the tax compliance and characteristics of noncompliant taxpayers. Pommerehne et al. (1994) conducted study in order to recognize the determinants of tax evasion. They used the presence of grievance in absolute terms in their study. Results indicated that as the sentiments of grievance increased in absolute terms, the level of tax evasion also increased and the level of tax moral belief decreased. Fisher et al. (1989) also examined the behavior of taxpayers in order to explore the behavioral determinants of tax evasion. He used random survey technique in order to acquire desired objectives like to identify the factors that motivate the tax compliance and characteristics of noncompliant taxpayers.

Skinner and Slemrod (1985) conducted a study in order to investigate the determinants of tax evasion. In this study, only strict economic determinants proposed by seminal models were taken. Study found that considerable share of effective tax compliance cannot be explained by using these solely variables. Srinivasan (1973) also introduced seminal theoretical models and conducted study while exploring the determinants of tax evasion. In this study, he explained that the behavior of tax evasion was based on level of risk aversion, amount of penalty imposed, and probability of being audited. Likewise, study found an ambiguous relationship between marginal tax rate or income and tax evasion. Alligham and Sandmo (1972) conducted study in order to examine the behavioral determinants of tax evasion by introducing a seminal theoretical model. In this study, he explained that the behavior of tax evasion was based on level of risk aversion, amount of penalty imposed, and probability of being audited. Moreover, study found an ambiguous relationship between marginal tax rate or income and tax evasion. Orewa (1957) conducted study and investigated the characteristics of tax evasion. Study found that high degree of inter-district mobility is the main reason of tax evasion on the part of taxpayers and argued that mobility of wage earners, salaried persons and self-employed persons with permanent and known addresses is an important factor of tax evasion because they keep themselves in movement from one place to another in order to earn legal money. He also found the reasons of partial evasion such as: resentment toward illiterate persons that present only their salaries and wages as taxable income, and traders maintain inadequate records. 


\section{Theoretical Background}

The Warner Model: Warner developed the RR technique in 1965. This innovative technique was originally developed in order to provide protection to the respondents when sensitive questions were asked from them. In this technique two logically opposite questions were asked from respondents and they were directed to answer one or other outcome which was depending upon the used device. For example: a question is asked about tax evasion which is logically a sensitive question. In order to get answer from respondent, a dice may be tossed along with determined outcomes such as:

- I have evaded tax.

- I have never evaded tax. [5 or 6]

Answer True or False

When respondent will asked to answer the question, he will said True or False and researcher will unable to understand that whether respondent is answering Q1 or Q2. This scenario will protect the privacy of respondents' answer. However, a statistical technique named as probability theory will help researcher to examine the associated sampling variance and to estimate proportion of answer relating to Q1 ( $\pi$ ) by using following equations:

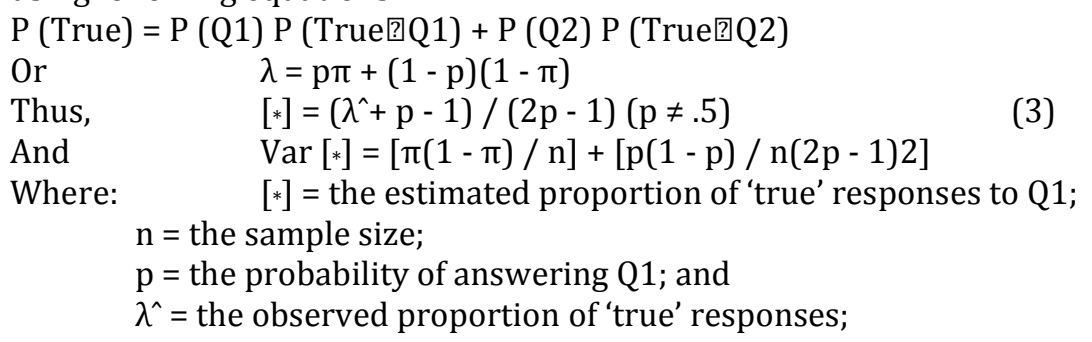

Moreover, it was claimed by Warner (1965) that RR technique can be used in order to reduce the nonresponses biases and responses biases which were originated from sensitive survey questions, therefore, this model will be suitable for attaining the sensitive questions because increase in estimator's variance due to the randomizing producer into design is one of the major drawback of this model.

\section{Methodology}

Sampling is an integral part. It includes: whom to survey; how many to survey; and how to select them. According to 2010 census, there are 271 cities in Pakistan and in this study 72 cities are targeted. Further, non-probability sampling technique is used in which each respondent does not have equal chance to select as sample. A questionnaire is developed and five point Likert scale is applied in questionnaire coded as strongly disagree $=1$, disagree $=2$, neutral $=3$, agree $=4$, and strongly agree $=5$. Total twelve hundred questionnaires are distributed among those respondents whose incomes fall in taxable range. In response, one-thousand and forty-three questionnaires are received; however, response rate is $86.92 \%$. Different statistical techniques like factor analysis to calculate factor loadings, standard deviation, arithmetic mean, percentages, Central Limit Theorem to know the correctness of factors based on probability, and correlation analysis are applied in this study while analyzing the data. Statistical Package for Social Sciences (SPSS) version 16 is used while analyzing the reliability of questions and this reliability is checked in terms of Cronbach's Alpha. In this study, Cronbach's Alpha of questions related to causes of tax evasion and avoidance is 0.676 .

\section{Results}

$$
\begin{aligned}
& \text { Variance }\left(\text { (ㅁ }^{2}\right)=\frac{\sum(\mathrm{X}-\mathrm{M})^{2}}{\mathrm{n}-1} \\
& =\frac{34372.4}{9}=3819.16 \\
& \text { Standard Deviation ( } \\
& =61.80
\end{aligned}
$$

Application of Central Limit Theorem (Z):

$$
\mathrm{Z}=\underline{\mathrm{X}-\mathrm{M}}
$$

Where: $\mathrm{X}=1043, \mathrm{M}=700.4, \mathrm{~S} . \mathrm{D}=61.80$ 


$$
\mathrm{Z}=\frac{1043-700.4}{61.80}=5.54
$$

Apply Cumulative Normal Distribution:

$$
\begin{aligned}
\operatorname{Pr}(\mathrm{Z} \geq 5.54) \rightarrow 1-\operatorname{Pr}(\mathrm{Z} & \leq 5.54) \\
& =1-(0.99997) \\
& =0.00003
\end{aligned}
$$

\begin{tabular}{|c|c|c|c|c|c|}
\hline Sr. & Particulars & $\begin{array}{l}\text { No. of } \\
\text { Samples that } \\
\text { Identified it } \\
\text { (X) }\end{array}$ & $\begin{array}{l}\text { Mean } \\
(\mathrm{M})\end{array}$ & $\mathbf{X}-\mathbf{M}$ & $(\mathrm{X}-\mathrm{M})^{2}$ \\
\hline 1 & Absence of tax morality & 777 & 700.4 & 76.6 & 5867.56 \\
\hline 2 & High tax rates & 666 & 700.4 & -34.4 & 1183.36 \\
\hline 3 & Illiteracy of tax calculation & 726 & 700.4 & 25.6 & 655.36 \\
\hline 4 & Lack of adequate enforcement for default & 760 & 700.4 & 59.6 & 3552.16 \\
\hline 5 & $\begin{array}{l}\text { Lack of adequate tax incentives } \\
\text { Non-existence of an equitable \& efficient }\end{array}$ & 709 & 700.4 & 8.6 & 73.96 \\
\hline 6 & tax system & 722 & 700.4 & 21.6 & 466.56 \\
\hline 7 & $\begin{array}{l}\text { No public enlightenment campaign } \\
\text { Poor Relationship of Tax Payers \& }\end{array}$ & 672 & 700.4 & -28.4 & 806.56 \\
\hline 8 & Authority & 748 & 700.4 & 47.6 & 2265.76 \\
\hline 9 & Poverty & 568 & 700.4 & -132.4 & 17529.76 \\
\hline 10 & $\begin{array}{l}\text { Proliferation of taxes } \\
\text { Total }\end{array}$ & $\begin{array}{l}656 \\
7004\end{array}$ & 700.4 & -44.4 & $\begin{array}{l}1971.36 \\
34372.4\end{array}$ \\
\hline
\end{tabular}

\section{Causes / Reasons of Tax Avoidance and Tax Evasion}

Table 1: Analysis of Reasons of Tax Avoidance and Evasion

Table 1 shows data regarding analysis of reasons of tax avoidance and evasion. In above computation, first of all, variance is calculated which is equal to 3819.16. Second, Standard Deviation is calculated which is equal to 61.80. Third, Central Limit Theorem is applied; where, value of $\mathrm{M}$ is equal to 700.4, value of $\mathrm{X}$ is equal to 1043, and value of S.D is equal to 61.80. In result, value of $\mathrm{Z}$ is equal to 5.54. In the last, cumulative normal distribution value through normal distribution calculator is calculated. The value in result is equal to zero which means there is hundred percent probability that all variables mentioned in favor of reasons of tax avoidance and evasion are correct.

Table 2: Top Five Reasons of Tax Avoidance and Evasion

\begin{tabular}{lllllll}
\hline Sr & Particulars & $\begin{array}{l}\text { Factor } \\
\text { Loadings }\end{array}$ & Rank & $\begin{array}{l}\text { Mean } \\
(\mathbf{M})\end{array}$ & Rank & $\begin{array}{l}\text { Standard } \\
\text { Deviation }\end{array}$ \\
\hline & $\begin{array}{l}\text { No public enlightenment } \\
\text { campaign }\end{array}$ & 0.508 & 1 & 3.68 & 5 & 1.09 \\
2 & Lack of adequate tax incentives & 0.493 & 2 & 3.80 & 2 & 1.06 \\
& $\begin{array}{l}\text { Poor Relationship of Tax Payers \& } \\
3\end{array}$ & 0.464 & 3 & 3.91 & 1 & 1.08 \\
4 & Authority & 0.456 & 4 & 3.78 & 3 & 1.08 \\
5 & Proliferation of taxes & 0.395 & 5 & 3.77 & 4 & 0.99 \\
\hline
\end{tabular}

Table 2 shows top five reasons of tax avoidance and tax evasion on the base of factor loadings and arithmetic mean. On the base of factor loadings, ranking of top five variables is in such manner: no public enlightenment campaign is at first; lack of adequate tax incentives is at second; poor relationship of tax payers \& authority is at third; proliferation of taxes is at fourth; and illiteracy of tax calculation is at fifth. On the other hand, on the base of arithmetic mean, poor relationship of tax payers \& authority is at first; lack of adequate tax incentives is at second; proliferation of taxes is at third; illiteracy of tax calculation is at fourth; and no public enlightenment campaign is at fifth. 
Table 3: Correlation Analysis of Causes / Reasons of Tax Avoidance and Evasion

\begin{tabular}{|c|c|c|c|c|c|c|c|c|c|c|}
\hline & 1 & 2 & 3 & 4 & 5 & 6 & 7 & 8 & 9 & 10 \\
\hline 1 & 1 & & & & & & & & & \\
\hline 2 & $0.194^{* *}$ & 1 & & & & & & & & \\
\hline 3 & $0.143^{* *}$ & $0.247^{* *}$ & 1 & & & & & & & \\
\hline 4 & $0.112^{* *}$ & $0.113^{* *}$ & $0.261^{* *}$ & 1 & & & & & & \\
\hline 5 & $0.191^{* *}$ & $0.096^{* *}$ & $0.178^{* *}$ & $0.295^{* *}$ & 1 & & & & & \\
\hline 6 & $0.152^{* *}$ & 0.008 & $0.079 *$ & $0.244^{* *}$ & $0.266^{* *}$ & 1 & & & & \\
\hline 7 & $0.213^{* *}$ & $0.140^{* *}$ & $0.123^{* *}$ & $0.172^{* *}$ & $0.264^{* *}$ & $0.265^{* *}$ & 1 & & & \\
\hline 8 & $0.176^{* *}$ & $0.088^{* *}$ & $0.063^{* *}$ & $0.233^{* *}$ & $0.224^{* *}$ & $0.244^{* *}$ & $0.324^{* *}$ & 1 & & \\
\hline 9 & $0.114^{* *}$ & $0.248^{* *}$ & $0.143^{* *}$ & $0.101^{* *}$ & $0.106^{* *}$ & 0.010 & $0.151^{* *}$ & $0.101^{* *}$ & 1 & \\
\hline 10 & $0.193^{* *}$ & $0.203^{* *}$ & $0.230 * *$ & $0.204^{* *}$ & $0.174^{* *}$ & $0.169 * *$ & $0.166^{* *}$ & $0.189 * *$ & $0.281^{* *}$ & 1 \\
\hline
\end{tabular}

*. Correlation is significant at the 0.05 level (2-tailed).

**. Correlation is significant at the 0.01 level (2-tailed).

Note: 1 = Absence of Tax Morality; 2 = High Tax Rates; 3 = Illiteracy of Tax Calculation; 4 = Lack of Adequate Enforcement for Default; 5 = Lack of Adequate Tax Incentives; $6=$ Non-Existence of an Equitable \& Efficient Tax System; 7 = No Public Enlightenment Campaign; 8 = Poor Relationship between Tax Authority \& Taxpayers; 9 = Poverty; and $10=$ Proliferation of Taxes.

Table 3 shows relationship between different causes / reasons of tax avoidance and tax evasion in Pakistan. First of all, on the base of above computation, all variables are, except variable 6 (Non-Existence of an Equitable \& Efficient Tax System) and variable 9 (Poverty), highly significantly positively correlated with each other. Second, there is no significant relationship between variable 6 (Non-Existence of an Equitable \& Efficient Tax System) and variable 2 (High Tax Rates); whereas, variable 6 (Non-Existence of an Equitable \& Efficient Tax System) is significantly correlated with variable 3 (Illiteracy of Tax Calculation) at $95 \%$ of confidence level. In the last, there is also no relationship exists between variable 9 (Poverty) and variable 6 (Non-Existence of an Equitable \& Efficient Tax System).

\section{Conclusion}

This study concludes: first of all, on the base of central limit theorem, there is $100 \%$ probability that all the variables regarding reasons, ways, and social and economic effects are correct. Furthermore, on the base of factor loadings, ranking of top five reasons/causes is in such manner: no public enlightenment campaign is at first; lack of adequate tax incentives is at second; poor relationship of tax payers \& authority is at third; proliferation of taxes is at fourth; and illiteracy of tax calculation is at fifth. On the base of correlation analysis, all variables are, except variable non-Existence of an equitable \& efficient tax system and poverty, highly significantly positively correlated with each other. There is no significant relationship between non-existence of an equitable \& efficient tax system and High Tax Rates; whereas, non-existence of an equitable \& efficient tax system is significantly correlated with illiteracy of tax calculation at $95 \%$ of confidence level. In the last, there is also no relationship exists between poverty and non-existence of an equitable \& efficient tax system.

Limitations, Future Research \& Policy Implications: This study focuses on exploration of major reasons/causes of tax avoidance and tax evasion from individual taxpayers of seventy two cities of Pakistan. This phenomenon can be extended up to many more cities of Pakistan and corporations can also be included in analysis to explore the reasons/causes of tax evasion and avoidance. Although, all those people whose income fall in taxable range are selected in population, but sample size is not sufficient for generalization of these results. In addition, heterogeneity between tax laws of different countries is also a big obstacle in generalization of these results.

It is also recommended that:

- A tax census should be conducted in a country to know about the actual number of taxpayers whether they are individuals or businessmen so that tax evasion incidences should be reduced;

- An audit unit should be established and tax clearance certificates should be issued to the taxpayers by the audit unit so that corrupt activities of tax officials could also be removed;

- Incentives should be announced to taxpayers on timely payment of tax without adopting any way of tax avoidance and evasion;

- New policies should not only be developed to remove reasons/causes of tax avoidance and evasion but also developed to reduce size of shadow economy because shadow economy is that economy in which people do not show their real income and taxable income that they have 
earned through legal activities including barter and monitory activities in order to avoid paying tax;

- Government should inform to the taxpayers about need for compliance and changes in tax legislation by using different means of publicity like walk-chalking, posters, banners, television, radio massages etc; and

- Revenue courts should be established that can punish tax evaders and avoiders through criminal sanctions and heavy monetary penalties.

\section{References}

Allingham, M. \& Sadmo, A. (1972). Income Tax Evasion: A Theoretical Analysis. Journal of Public Economics, 1, 323-338.

Boylan, S. \& Sprinkle, G. (2001). Experimental Evidence on the Relation between Tax Rates and Compliance: The Effect of Earned vs. Endowed Income. Journal of the American Taxation Association, 23(1), 75-90.

Fisher, R., Goddeeris, J. \& Young, J. (1989). Participation in Tax Amnesties: The Individual Income Tax. National Tax Journal, 42(2), 15-27.

Lefebvre, M., Pestieau, P., Riedl, A. \& Villeval, M. C. (2011). Tax Evasion, Welfare Fraud, and the Broken Windows Effect: An Experiment in Belgium, France and the Netherlands. IZA Discussion Paper No. 5609.

Orewa, G. O. (1957). Taxation in Western Nigeria. London Oxford University Press.

Pommerehne, W., Hart, A. \& Frey, B. (1994). Tax Morale, Tax Evasion and the Choice of Policy Instruments in Different Political Systems. Public Finance, 49, 52-69.

Schneider, F. \& Enste, H. D. (2000). Shadow Economies around the World - Size, Causes, and Consequences. IMF Working Papers 00/26.

Skinner, J. \& Slemrod, J. (1985). An Economic Perspective on Tax Evasion. National Tax Journal, 38, 345353.

Srinivasan, T. (1973). Tax Evasion: A Model. Journal of Public Economics, 2(3), 339-346.

Uadiale, O. M., Fagbemi, T. O. \& Ogunleye, J. O. (2010). An Empirical Study of the Relationship between Culture and Personal Income Tax Evasion in Nigeria. European Journal of Economics, Finance and Administrative Sciences, 20, 116-126.

Warner, S. (1965). Randomized response: a survey technique for eliminating evasive answer bias. Journal of the American Statistical Association, 60, 63-69. 